\title{
Penggunaan "Teknik Jalinan Cerita" untuk meningkatkan penguasaan dan ingatan pelajar terhadap kata majmuk bentuk mantap
}

\author{
Using Storytelling Techniques to improving the mastery and memory of compound words \\ composed in Malay Language among students \\ Wong Shia Ho \\ wsh@ipbl.edu.mv \\ Institut Pendidikan Guru Kampus Batu Lintang, Kuching, Sarawak, Malaysia
}

DOI: https://doi.org/10.37134/pendeta.vol10.8.2019

\begin{abstract}
ABSTRAK
Kajian ini dijalankan untuk melihat kesan penggunaan "Teknik Jalinan Cerita" dalam usaha membantu pelajar menguasai dan mengingati 15 kata majmuk bentuk mantap bahasa Melayu. Kajian ini juga untuk menambah baik amalan pengajaran dan pembelajaran saya ketika mengajarkan topik kata majmuk. Selain diri saya, peserta kajian terdiri daripada 38 orang pelajar semester satu berpengkhususan bahasa Melayu di bawah Program Ijazah Sarjana Muda Perguruan. Data kajian dikumpul melalui lembaran kerja dan soal selidik. Penyemakan data dilakukan melalui triangulasi antara kaedah, sumber dan masa. Hasil analisis data mendapati bahawa "Teknik Jalinan Cerita" dapat membantu pelajar menguasai kata majmuk bentuk mantap selain menambah baik amalan pengajaran dan pembelajaran guru. Walau bagaimanapun, mereka lupa akan kata majmuk tersebut apabila diuji setelah tiga bulan. Oleh itu, kajian ini bercadang untuk memasukkan elemen latih tubi terhadap "Teknik Jalinan Cerita" ini pada masa akan datang kerana dijangka dapat menghasilkan kesan yang lebih positif.
\end{abstract}

Kata kunci: Kata Majmuk, Bahasa Melayu, Teknik Jalinan Cerita

\section{ABSTRACT}

This research was conducted to examine the effect of using storytelling techniques in order to enhance the mastery of 15 compound words composed in Malay language among students. This study also aims to improve my teaching and learning $(P d P)$ practice while teaching the topic of compound words. Apart from myself, the participants consisted of 38 semesters one students under the Bachelor of Education Degree Program (PISMP) whom specializes in Malay language. The data were collected through questionnaires and interviews. Data checking are done through triangulation between methods, resources and time. The results of the data analysis found that the storytelling technique of the 15 compound words was able to increase the mastery of the students in compound words as well as to improve the teacher's teaching and learning practice. However, the participants tend to forget the compound words after three months. I would like to extend this study by inserting the drill element into the storytelling technique which is expected to produce a more positive effect on the mastery of compound words among students.

Keywords: Compound words, Malay language, Storytelling techniques

\section{PENGENALAN}

Pengalaman sebagai guru atau pensyarah bahasa Melayu sudah semestinya perlu mengajarkan tatabahasa bahasa Melayu. Hal ini kerana seseorang pelajar perlulah menguasai tatabahasa dan ada kalanya perlu mengingati contoh-contoh yang terhad bilangannya bagi memperkukuh penjelasan sesuatu rumus bahasa yang dibincangkan. Oleh itu. ada pelajar menghafalnya, ada pula menjadikannya satu akronim agar mudah diingati, malah ada yang memindahkan maklumat tersebut dalam gambar rajah dan sebagainya. Dalam 
pengajian bahasa Melayu di Institusi Pendidikan Guru (IPG), kata majmuk diajarkan secara langsung dalam kursus "Morfologi Bahasa Melayu (Kod Kursus: BMM1054)" dan kursus "Linguistik Terapan Bahasa Melayu (Kod Kursus: BMM3023)". Kata majmuk ialah bentuk kata yang wujud apabila dua kata dasar atau lebih dirangkaikan menjadi satu kesatuan sintaksis yang membawa makna tertentu. Kata majmuk dieja terpisah dan bertindak sebagai satu unit, iaitu bentuknya tidak boleh menerima sebarang penyisipan unsur lain. Misalnya, "kerusi malas" ialah kata majmuk kerana tidak dapat disisipkan unsur lain seperti "yang". Sebaliknya "pinggan mangkuk" bukan kata majmuk kerana dapat diselitkan kata hubung "dan" Pada dasarnya, kata majmuk dieja terpisah. Walau bagaimanapun, terdapat sebilangan kecil (15 perkataan) bentuk kata majmuk yang penggunaannya sudah dianggap mantap sebagai satu perkataan yang utuh dan dieja bercantum (Nik Safiah Karim, Farid M. Onn, Hashim Musa \& Abdul Hamid Mahmood, 2014:72), iaitu:
- antarabangsa
- beritahu
- bumiputera
- jawatankuasa
- kakitangan
- kerjasama
- olahraga
- matahari
- setiausaha
- sukarela
- suruhanjaya
- tandatangan
- tanggungjawab
- warganegara
- pesuruhjaya

Melalui penulisan akademik peserta kajian, didapati bahawa kesilapan ejaan kata majmuk berlaku. Sebagai contoh, melalui slaid pembentangan semasa kelas tutorial, ada pelajar yang mengeja kata majmuk "mengenal pasti" dengan ejaan rapat atau bercantum sehingga menjadi "mengenalpasti". Dengan ini, difikirkan bahawa perlu ada satu cara untuk mengatasi masalah ini. Maka "Teknik Jalinan Cerita" diaplikasikan kepada peserta kajian sewaktu mengajarkan topik "kata majmuk".

\section{TUJUAN KAJIAN}

Kajian ini dijalankan bertujuan untuk mencadangkan satu teknik pengajaran yang dapat diaplikasikan oleh guru-guru bahasa Melayu ketika mengajarkan kata majmuk mantap agar pelajar lebih mudah menguasai dan mengingatinya.

\section{OBJEKTIF KAJIAN}

Kajian ini dijalankan adalah untuk:

1. Menunjukkan kesan "Teknik Jalinan Cerita" untuk membantu pelajar menguasai kata majmuk bentuk mantap.

2. Menunjukkan kesan "Teknik Jalinan Cerita" untuk meningkatkan ingatan pelajar tentang kata majmuk bentuk mantap. 
3. Menunjukkan penambahbaikan amalan pedagogi guru dalam pengajaran kata majmuk bentuk mantap melalui penggunaan "Teknik Jalinan Cerita".

\section{SOALAN KAJIAN}

Kajian ini dijalankan bagi menjawab tiga soalan kajian berikut:

1. Bagaimanakah penggunaan "Teknik Jalinan Cerita" dapat meningkatkan penguasaan pelajar terhadap kata majmuk bentuk mantap?

2. Bagaimanakah penggunaan "Teknik Jalinan Cerita" dapat meningkatkan ingatan pelajar terhadap kata majmuk bentuk mantap?

3. Bagaimanakah amalan pedagogi guru dalam pengajaran dan pembelajaran kata majmuk bentuk mantap dapat ditambah baik melalui penggunaan "Teknik Jalinan Cerita"?

\section{PERNYATAAN MASALAH}

Pemilihan isu keprihatinan ini dilakukan atas kesedaran bahawa pengejaan sesuatu perkataan dengan betul dalam pembelajaran bahasa amatlah penting. Kesilapan ejaan akan menjejaskan makna sesuatu penyampaian bahasa. Topik "kata majmuk" bukanlah asing kepada pelajar Program Ijazah Sarjana Muda Perguruan (PISMP) Bahasa Melayu kerana mereka telah didedahkan tentang "kata majmuk" sewaktu di bangku sekolah lagi. Malah kata majmuk ini diajarkan juga semasa mereka mengikuti kursus Morfologi Bahasa Melayu (BMM1054) di IPG.

Tinjauan awal dilakukan mendapati bahawa mereka bukan sahaja jelas tentang maksud dan contoh "kata majmuk" malah dapat membezakan kata majmuk dengan bentuk kata lain, iaitu kata tunggal, kata terbitan, mahupun kata ganda. Hal ini dapat ditunjukkan seperti dalam Rajah 1 yang berikut:

Nama:

Arahan : Hitamkan jawapan yang paling betul.

(1) Apakah yang dimaksudkan dengan kata majmuk?

(a) Proses yang menggandakan kata dasar.

(b) Perkataan yang belum menerima sebarang imbuhan. 1 (R25)

(c) Bentuk perkataan yang dihasilkan melalui proses pengimbuhan.

(d) Hasil proses merangkaikan dua kata dasar atau lebih yang membawa makna yang

khusus. (37 orang)

(2) Yang manakah kata majmuk?
(a) Makan (1 orang, R25)
(b) Kura-kura
(c) Jalan raya (37 orang)
(d) Kemerdekaan

RAJAH 1: Soalan Pengenalan tentang Kata Majmuk

Berdasarkan Rajah 1 di atas, didapati bahawa daripada 38 orang (97.4\%) peserta kajian yang diuji, sebanyak 37 orang atau $97.5 \%$ daripada mereka dapat menyatakan maksud dan contoh "kata majmuk". Hal ini bermaksud hampir semua peserta kajian mempunyai pengetahuan sedia ada mengenainya. Hanya ada seorang peserta kajian (2.5\%) tidak dapat menjawab kedua-dua soalan tersebut. 
Apabila kesemua peserta kajian (38 orang) ini diminta menyenaraikan kata majmuk bentuk mantap, pencapaian mereka dapat digambarkan melalui Rajah 2 seperti yang berikut:

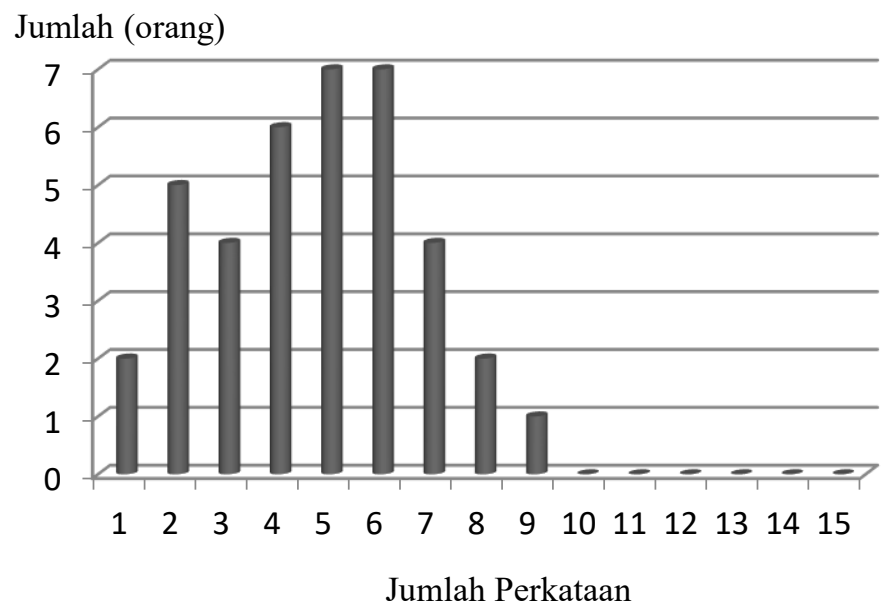

- Kata Majmuk Bentuk Mantap

\section{RAJAH 2: Hasil Tinjauan Awal Pencapaian Peserta Kajian}

Berdasarkan Rajah 2 di atas, didapati bahawa hanya seorang peserta kajian berjaya menyenaraikan sembilan kata majmuk bentuk mantap (jumlah keseluruhan ialah 15). Yang lain hanya dapat menyenaraikannya kurang daripada sembilan. Hal ini menunjukkan bahawa para peserta kajian belum dapat menguasai kata majmuk bentuk mantap dengan baik. Dua contoh jawapan mereka dapat ditunjukkan dalam Rajah 3 seperti yang berikut:

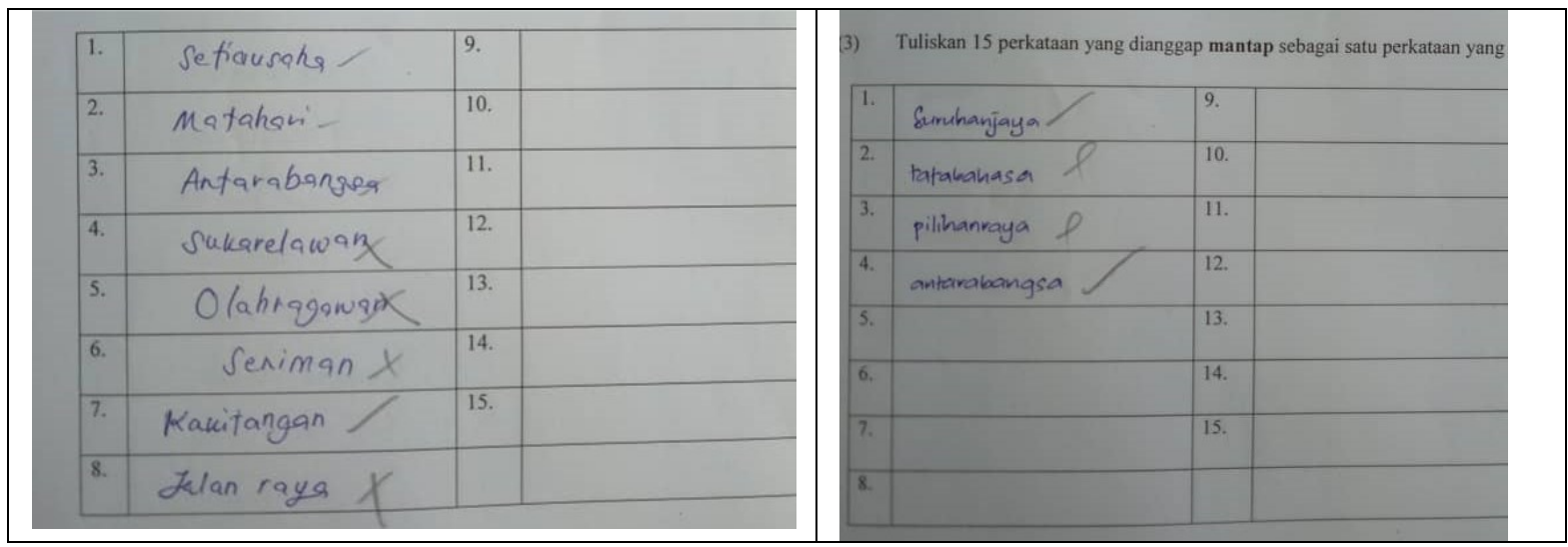

Peserta Kajian 1

Peserta Kajian 2

RAJAH 3: Contoh Jawapan Dua orang Peserta Kajian melalui Tinjauan Awal

Melalui Rajah 3 di atas, didapati bahawa peserta kajian bukan sahaja belum dapat mengemukakan kesemua 15 kata majmuk bentuk mantap tetapi juga ada antara mereka menyenaraikan kata lain sebagai kata majmuk bentuk mantap.

Melalui refleksi ketika mengajarkan "kata majmuk", didapati bahawa teknik yang saya gunakan semasa pengajaran dan pembelajaran (PdP) mungkin lebih menekankan penyampaian maklumat daripada penguasaan dan ingatan kepada pelajar. Hal ini kerana, semasa kata majmuk diajarkan, para pelajar hanya dijelaskan maksud, bentuk ejaan kata majmuk, iaitu ejaan terpisah dan ejaan bercantum. 15 ejaan kata majmuk bentuk mantap pula hanya disenaraikan pada slaid PowerPoint dan kurangnya penekanan khusus untuk mengingati contoh-contoh tersebut. Suasana PdP yang lebih bersifat syarahan ini sedikit sebanyak 
menjejaskan keseronokan belajar. Kekurangan pengajaran bersifat syarahan ini disifatkan oleh Alizah Lambri \& Zamri Mahamod (2015) sebagai kaedah pengajaran yang bersifat suapan dan tidak lagi sesuai dengan pembaharuan kurikulum dan perubahan budaya belajar dan budaya mengajar. Kajian ini berpendapat bahawa pernyataan Alizah Lambri \& Zamri Mahamod ada kebenarannya kerana pelajar telah gagal untuk menyenaraikan kesemua 15 kata majmuk mantap tersebut selepas disampaikan secara syarahan tersebut.

Kekurangan dalam PdP ini perlu diatasi dengan teknik yang sesuai dan menyeronokkan agar mereka dapat menguasai dan mengingati kata majmuk bentuk kekecualian tersebut. Oleh itu, "Teknik Jalinan Cerita" digunakan untuk menyelesaikan masalah ini kerana kajian terdahulu oleh Tay \& Wong (2016) menunjukkan bahawa pelajar amat mengharapkan suasana pembelajaran yang menarik dan ceria dengan melibatkan unsur didik hibur, teknologi maklumat dan komunikasi (TMK) dan unsur jenaka. Kajian ini berpendapat bahawa teknik didik hibur juga merangkumi unsur cerita. Malah menurut Shahabuddin Hashim, Rohizani Yaakub \& Mohd Zohir Ahmad (2007) \& Loi (2012), teknik bercerita pernah menjadi kaedah yang dominan suatu ketika dahulu sebagai teknik untuk menarik perhatian pelajar kerana teknik bercerita mengambil kira imaginasi dan kreativiti serta mempunyai plot yang baik dan mengandungi mesej yang menarik. Hal ini diperkukuh oleh Siti Zuhaidah Zakeria \& Nik Rafidah Nik Muhamad Affendi (2014) yang menyatakan bahawa cerita-cerita rakyat dalam majalah Dewan Pelajar kerap menjadi tumpuan dan digemari oleh pembacanya kerana para pembacanya (kanak-kanak) memberikan komen positif dan menjadikan ruangan "Cerita Rakyat" tersebut sebagai ruangan kegemaran mereka.

Kesan dan keupayaan teknik bercerita dapat dilihat melalui kajian Zuraini Jusoh \& Abdul Rasid Jamian (2014) yang membuktikan bahawa teknik bercerita memberikan kesan yang positif kepada prestasi penulisan karangan murid. Malah Powell dan Murray (2012) dalam kajian mereka tentang penggunaan strategi bercerita dalam pengajaran aspek pemahaman secara dalam talian juga membuktikan bahawa bahan pengajaran dalam format cerita meskipun disampaikan secara dalam talian juga mampu meningkatkan pemahaman dan pencapaian pelajar terhadap teori dan konsep yang sukar.

\section{PERANCANGAN DAN PELAKSANAAN KAJIAN}

"Teknik Jalinan Cerita" digunakan dalam kajian ini. Penggunaan teknik dalam kajian ini amatlah relevan kerana kata-kata majmuk tersebut dapat dijalinkan untuk menghasilkan sebuah cerita yang menarik dan bermakna. Teknik ini terhasil melalui refleksi kendiri tentang PdP yang saya laksanakan ketika mengajarkan kata majmuk mantap. Jalinan cerita yang saya hasilkan dan gunakan dalam kajian ini ditunjukkan dalam Rajah 4 seperti yang berikut: 
Penggunaan "Teknik Jalinan Cerita" untuk meningkatkan penguasaan dan ingatan pelajar terhadap kata majmuk bentuk mantap

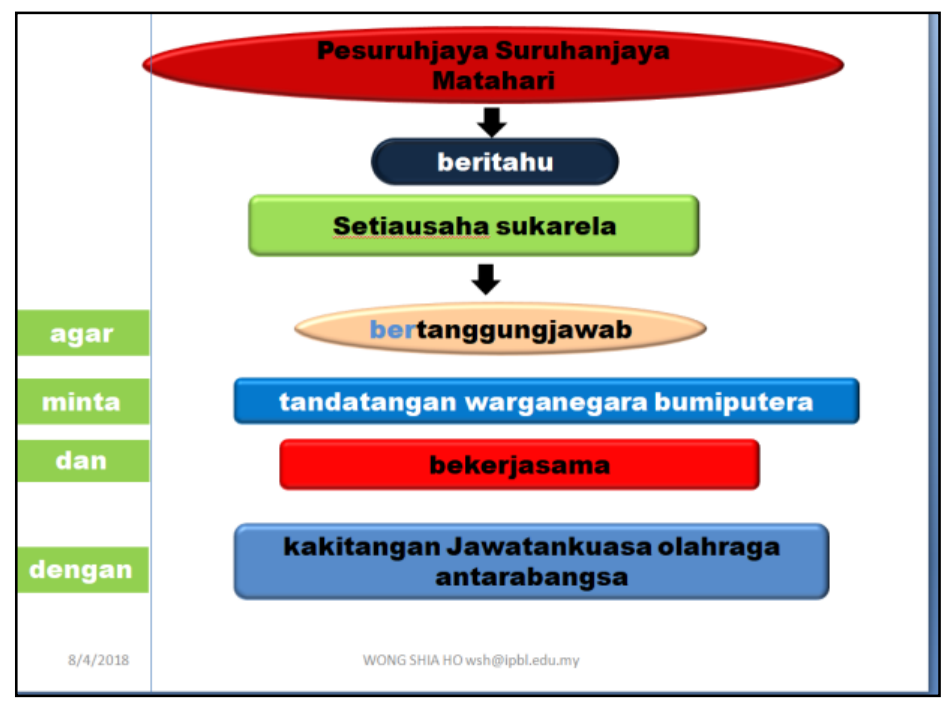

RAJAH 4: Jalinan Cerita 15 daripada Kata Majmuk Bentuk Mantap

Berdasarkan Rajah 4 di atas, kesemua 15 kata majmuk bentuk mantap dijalinkan sehingga terhasilnya satu cerita dengan bantuan beberapa kata sampingan, iaitu "agar", "minta", "dan", dan "dengan". Selain itu, imbuhan "ber" turut digunakan. Cerita yang dimaksudkan ialah:

"Pesuruhjaya suruhanjaya matahari beritahu setiausaha sukarela agar ber-tanggungjawab minta tandatangan warganegara bumiputera dan be-kerjasama dengan kakitangan jawatankuasa olahraga antarabangsa”.

Cerita yang dihasilkan daripada 15 kata majmuk mantap tersebut dilakukan melalui pertimbangan yang teliti agar cerita tersebut bermakna dan mempunyai kesatuan idea malah perlu bersifat realistik agar mudah difahami oleh pelajar. Hal ini kerana menurut Zulkifli Osman, Anida Sarudin, Dahlia Janan dan Ani Omar (2016), pengajaran dan pembelajaran di bilik darjah tidak boleh dipisahkan daripada realiti dunia luar. Dengan mengambil kira pandangan tersebut, cerita yang terhasil ini lebih berupa satu pernyataan tentang "arahan daripada pihak atasan kepada anak-anak buahnya untuk melakukan sesuatu tindakan". Hal ini mudah difahami oleh pelajar kerana dalam kehidupan sebenar khususnya ketika sebagai pelajar, mereka juga sering kali menerima arahan daripada pensyarah mereka.

Penjalinan kata majmuk bentuk mantap menjadi satu cerita lengkap dilihat bukan sahaja mampu mengatasi pembelajaran peserta kajian tetapi juga dapat meningkatkan penguasaan dan ingatan peserta kajian. Hal ini mengambil kira pandangan daripada penulisan dan dapatan kajian terdahulu yang berkaitan dengan penggunaan teknik bercerita dalam pengajaran. Menurut González (2010), bercerita ialah alat yang idea untuk pembelajaran bahasa. Melalui aktiviti bercerita, para pelajar dapat mempelajari bahasa dalam keadaan yang menarik, melucukan dan sukar dilupakan. Malah para pelajar dapat menyerap bahasa yang dipelajari dengan tahap yang luar biasa apabila aktiviti tersebut menyeronokkan mereka. Pernyataan tersebut selaras dengan pendapat Liu (2016) bahawa murid suka mendengar guru bercerita. Semasa mendengar cerita, murid akan lebih berfokus kerana ingin mengikuti cerita tersebut sampai akhirnya. Oleh itu, guru boleh menjadikan aktiviti bercerita sebagai sebahagian daripada proses pengajaran dan pembelajaran mereka. Menurut Liu lagi, melalui aktiviti bercerita, guru boleh menunjukkan unsur tatabahasa terutamanya dari segi penggunaannya dalam situasi sebenar.

Sebenarnya teknik bercerita bukan sahaja diminati oleh kanak-kanak atau remaja sahaja. Dalam kajian yang dilakukan oleh Nguyen, Stanley \& Stanley (2014) terhadap golongan dewasa, iaitu 15 orang tenaga pengajar bahasa Cina sebagai bahasa asing dan 30 orang pelajar dewasa di Universiti Perguruan Shaanyi (陕西师范大学) di Xi' an, China（中国, 西安) yang mengikuti kursus bahasa Cina sebagai bahasa 
asing dari segi minat, penglibatan, manfaat, dan cabaran yang dihadapi oleh mereka sewaktu teknik bercerita dilaksanakan dalam pengajaran bahasa, hasil kajian tersebut menunjukkan bahawa para responden amat meminati teknik bercerita kerana kemampuannya menghasilkan pembelajaran bahasa secara berkesan.

Dalam kajian ini, cerita yang dibentuk daripada 15 kata majmuk mantap ini selain disampaikan secara lisan juga disokong oleh media lain agar lebih berkesan. Hal ini mengambil pandangan DeNeen (2012) bahawa semasa bercerita, pancaindera pendengar perlu dimaksimumkan. Oleh itu, kajian ini menayangkan cerita yang telah dibentuk daripada 15 kata majmuk tersebut dengan menggunakan slaid PowerPoint (Sila rujuk Rajah 3) agar pelajar dapat melihat selain mendengarnya. Malah DeNeen juga menyatakan bahawa bahawa cerita hendaklah ditulis dalam satu ayat sebelum seseorang mula bercerita agar cerita yang hendak disampaikan mudah diikuti. Dalam kajian ini, kesemua 15 kata majmuk diusahakan sehingga terbentuk satu ayat adalah semata-mata untuk mencapai kesan yang diharapkan, iaitu mudah difahami. Hal ini juga membantu ingatan pelajar apabila 15 kata majmuk tersebut menjadi kesatuan. Hal ini selaras dengan pendapat Mohd. Ghani Awang (1996) bahawa "untuk ingatan, adalah lebih baik mempelajari keseluruhan bahagian daripada sebahagiannya sahaja" (m.s.6). Pembelajaran lebih bermakna jika menarik minat murid dan pelajar akan mudah mengingati pelajaran yang diikutinya jika pengetahuan tersebut biasa kepada diri pelajar.

Selain itu, jalinan cerita tersebut saya lukiskan pada slaid dengan pelbagai warna. Hal ini mengambil kira pandangan Ramlan Hamzah \& Lily Mastura Harun (2005:12) bahawa warna dan kepelbagaian grafik akan menambah seronok dan tumpuan. Setiap perkataan dalam kata majmuk bukan sahaja dijalinkan menjadi satu cerita dengan setiap warna bagi perkataan tersebut tetapi juga dilakarkan dalam bentuk grafik, iaitu, carta aliran yang memperlihatkan aliran maklumat berbentuk "arahan" daripada "pesuruhjaya suruhanjaya matahari" kepada "setiausaha sukarela" mengenai "tugas-tugas yang perlu dilaksanakan". Hal ini mengambil kira pandangan Ramlan Hamzah \& Lily Mastura Harun (2005:74) bahawa pengurusan grafik merupakan alat yang dapat membantu anda mentadbir maklumat yang diterima dalam bentuk visual yang menarik.

Berdasarkan tinjauan terhadap penulisan dan kajian yang terdahulu khususnya tentang kemampuan teknik bercerita dalam PdP, kajian ini mengaplikasikan "Teknik Jalinan Cerita" untuk meningkatkan penguasaan dan ingatan tentang kata majmuk bentuk mantap dalam kalangan peserta kajian di samping menambah baik PdP diri saya tentang bentuk kata tersebut.

Dari segi pelaksanaan tindakan pula, kajian ini dilaksanakan dalam tempoh tiga bulan. Sebelum kata majmuk diperkenalkan kepada peserta kajian. kajian ini melakukan tinjauan awal untuk melihat pemahaman mereka tentang kata majmuk mantap. Tinjauan awal ini dilakukan melalui lembaran kerja. Sebaik-baik sahaja lembaran kerja telah dijawab dan dikutip, maka PdP dimulakan dengan peserta kajian akan diperkenalkan definisi kata majmuk, jenis kata majmuk, dan kata majmuk bentuk mantap. Ketika PdP, slaid tentang "kata majmuk bentuk mantap" ditunjukkan dalam Rajah 5 seperti yang berikut:

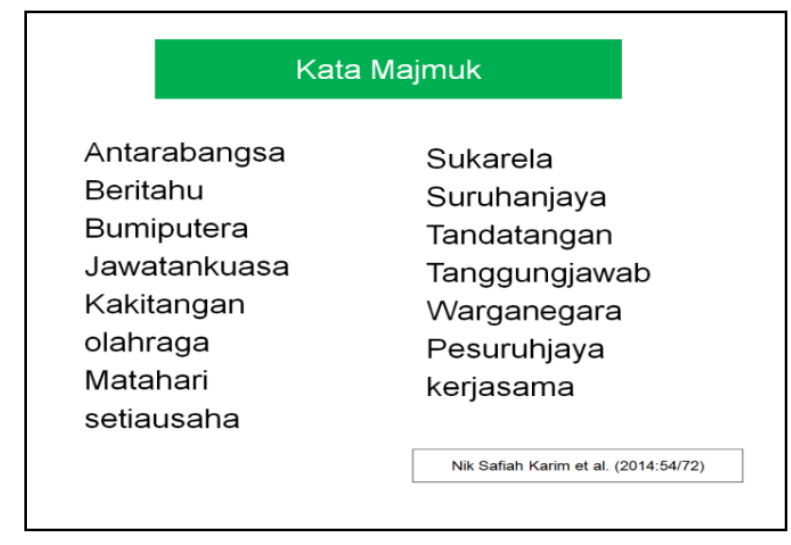

RAJAH 5: Slaid PowerPoint: Senarai Kata Majmuk Bentuk Mantap 
Rajah 5 di atas menunjukkan kata majmuk mantap yang ditulis pada slaid PowerPoint hanya berbentuk penyenaraian biasa. Pelajar diminta membacanya sebanyak dua kali. Setelah itu, slaid ini akan dipadamkan. Kemudian, peserta kajian dikehendaki menyenaraikan 15 kata majmuk mantap tersebut. Selepas jawapan peserta kajian dikutip, slaid yang mengandungi berbentuk cerita daripada 15 kata majmuk (Sila lihat Rajah 3: Jalinan Cerita daripada 15 Kata Majmuk Mantap) ditayangkan. Para peserta kajian diberitahu bahawa 15 kata majmuk ini telah dijalinkan menjadi cerita. Peserta kajian dibimbing untuk membacanya sebanyak dua kali. Sebaik-baik sahaja selesai membacanya, mereka diminta menyenaraikan kesemua 15 perkataan tersebut seperti yang ditunjukkan dalam Rajah 6 seperti yang berikut:

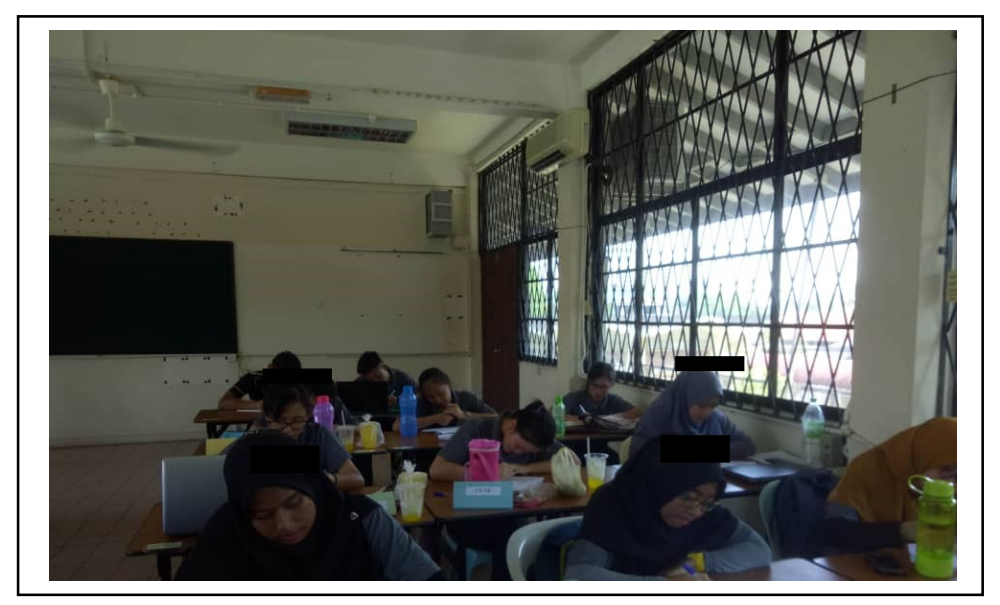

\section{KAEDAH KAJIAN}

Kesemua 38 orang pelajar IPG di sebuah kampus yang mengambil pengkhususan bahasa Melayu di bawah Program Ijazah Sarjana Muda Perguruan (PISMP) telah menjadi peserta kajian. Melalui tinjauan awal, mereka didapati tidak dapat menguasai 15 kata majmuk dalam bentuk mantap. Saya turut serta sebagai peserta kajian kerana ingin menambah baik amalan pengajaran saya dari segi kemahiran PdP tentang tajuk "kata majmuk".

Kajian ini turut mengambil kira aspek etika penyelidikan yang perlu dipatuhi. Menurut Othman Mohamed (2001) dan Bailey (1984), isu yang paling hampir dengan kod etika ialah yang berkaitan dengan persoalan mendapatkan persetujuan melaksanakan penyelidikan dan isu perlunya menjaga hak serta keselamatan subjek. Menurut Bailey lagi, etika juga berkaitan dengan penganalisisan data seperti penyelidik mungkin melanggar kesusilaan apabila menganalisis data dengan hanya mendedahkan sebahagian fakta, mengemukakan fakta yang terkeluar daripada konteks, memalsukan penemuan, atau mengemukakan fakta yang mengelirukan, seperti "menipu melalui perangkaan". Bagi mengelakkan keadaan ini berlaku, kesemua pelajar (38 orang) ini telah diberitahu tentang tujuan penilaian dibuat terhadap mereka semata-mata untuk meningkatkan mutu PdP saya. Malah, lembaran kerja yang digunakan sebagai bahan penilaian tidak perlu diisi dengan maklumat demografi peserta kajian secara terperinci. Peserta kajian juga diberitahu bahawa nama yang ditulis dalam soal selidik tersebut tidak dilaporkan dalam kajian ini. Data-data yang diperoleh dalam kajian ini dianalisis dengan berdasarkan tujuan kajian secara jujur dan objektif, dan tidak dipengaruhi oleh emosi atau fitnah yang boleh menghancurkan nilai sesuatu masyarakat.

Dari segi pengumpulan data, kajian ini menggunakan lembaran kerja dan soal selidik. Lembaran kerja yang digunakan untuk mengumpul data kajian ditunjukkan dalam Rajah 7 seperti yang berikut: 


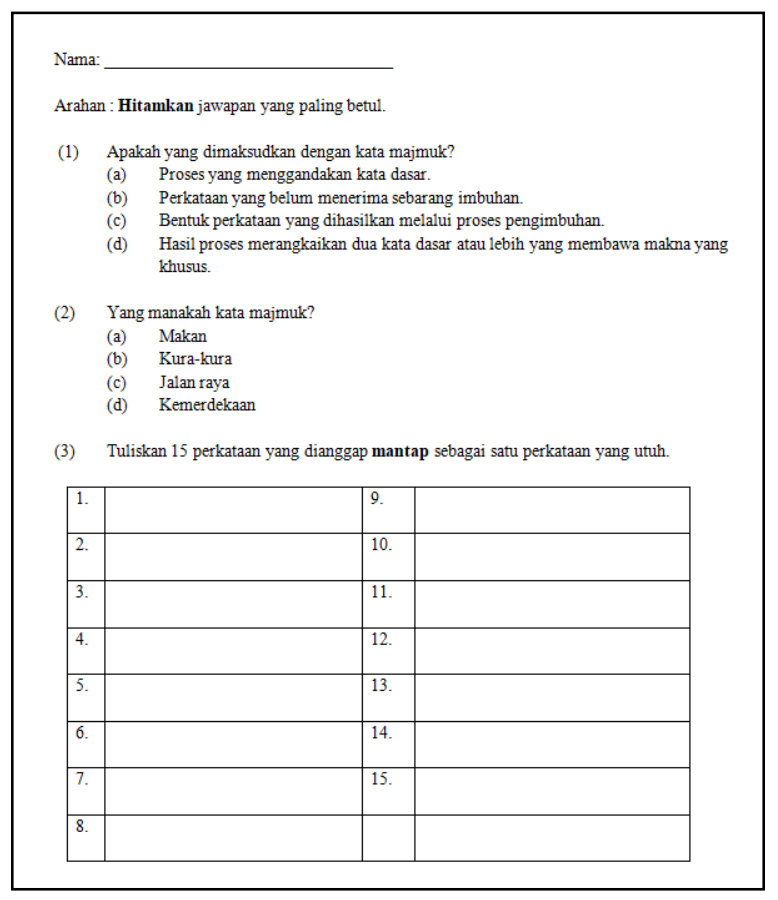

RAJAH 7: Lembaran Kerja untuk Tinjauan Awal, Peringkat Penyenaraian, Peringkat Selepas "Teknik Jalinan Cerita", dan Peringkat "Ujian Mengejut"

Lembaran kerja yang ditunjukkan pada Rajah 7 di atas mengandungi tiga soalan. Soalan (1) tentang maksud kata majmuk, Soalan (2) tentang contoh kata majmuk, Soalan (3) mengehendaki subjek kajian menyenaraikan kata majmuk mantap yang diketahui mereka. Pada peringkat tinjauan awal, para pelajar dikehendaki menjawab ketiga-tiga soalan tersebut. Lembaran kerja tersebut digunakan semula selepas kata majmuk diajarkan secara penyenaraian, selepas pengaplikasian "Teknik Jalinan Cerita", dan semasa ujian mengejut (selepas tiga bulan "Teknik Jalinan Cerita" diaplikasikan). Walau bagaimanapun, Soalan (1) dan (2) dalam lembaran kerja tersebut tidak perlu lagi dijawab pada ketiga-tiga peringkat ini. Mereka hanya perlu menjawab Soalan (3) sahaja.

Soal selidik turut digunakan untuk memperoleh maklumat dan pandangan peserta tentang penggunaan "Teknik Jalinan Cerita" tersebut. Soal selidik yang digunakan dalam kajian ini ditunjukkan seperti dalam Rajah 8 yang berikut: 


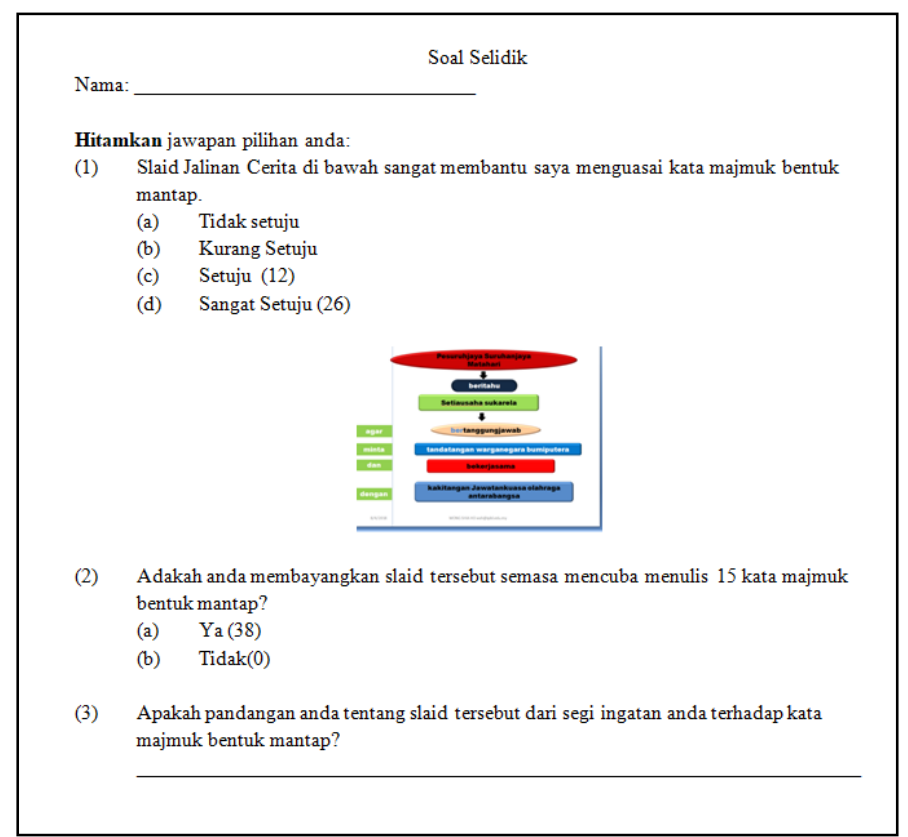

RAJAH 8: Soal Selidik selepas Teknik Jalinan Cerita

Soal selidik yang ditunjukkan pada Rajah 8 di atas mengandungi tiga soalan yang berkaitan dengan pandangan mereka tentang "Teknik Jalinan Cerita" yang diaplikasikan dalam kajian ini. Soalan yang dikemukakan adalah berkaitan dengan kesan dan kebergantungan mereka terhadap teknik ini.

Dari segi teknik penganalisisan data pula, kesemua data kajian bagi objektif kajian (1), (2) dan (3) dianalisis secara kuantitatif deskriptif, iaitu kekerapan atau frekuensi, dan peratusan. Walau bagaimanapun, objektif kajian (3) turut dianalisis secara kualitatif deskriptif bagi memperkukuh dapatan yang diperoleh secara kuantatif yang berkaitan dengan kesan jalinan cerita terhadap ingatan peserta kajian kepada kata majmuk bentuk mantap. D

Penyemakan data turut diaplikasikan dalam kajian ini, sehubungan dengan itu, triangulasi kaedah, sumber dan masa sebagai teknik digunakan untuk menyemak data. Hal ini selaras dengan pendapat Merriam (1998) bahawa triangulasi meningkatkan kebolehpercayaan penyelidikan. Triangulasi kaedah dilakukan dengan membandingkan data yang dikumpul melalui pelbagai kaedah, iaitu lembaran kerja dan soal selidik. Data daripada pelbagai sumber dianalisis dengan teliti bagi memastikan kredibilitinya terpelihara. Triangulasi masa dijalankan dengan membandingkan hasil tinjauan awal, selepas pengajaran kata majmuk secara penyenaraian dan selepas "Teknik Jalinan Cerita" digunakan. Triangulasi sumber turut dilakukan dalam kajian ini dengan mendapatkan pandangan seorang pensyarah kanan Jabatan Pengajian Melayu yang berpengalaman dan berpengkhususan linguistik bagi memastikan kesahan data dan penyemakan data dan mengelakkan perkara penting terlepas pandang sepanjang kajian ini dijalankan.

\section{DAPATAN KAJIAN}

Dapatan kajian ini dihuraikan mengikuti susunan objektif kajian yang telah ditentukan dan dinyatakan sebelum ini. 


\section{Kesan “Teknik Jalinan Cerita” untuk Membantu Pelajar Menguasai Kata Majmuk Bentuk Mantap.}

Melalui "Teknik Jalinan Cerita" yang diaplikasikan kepada peserta kajian, penguasaan kata majmuk mantap dalam kalangan peserta kajian semakin meningkat. Hal ini dapat ditunjukkan melalui Rajah 9 seperti yang berikut:

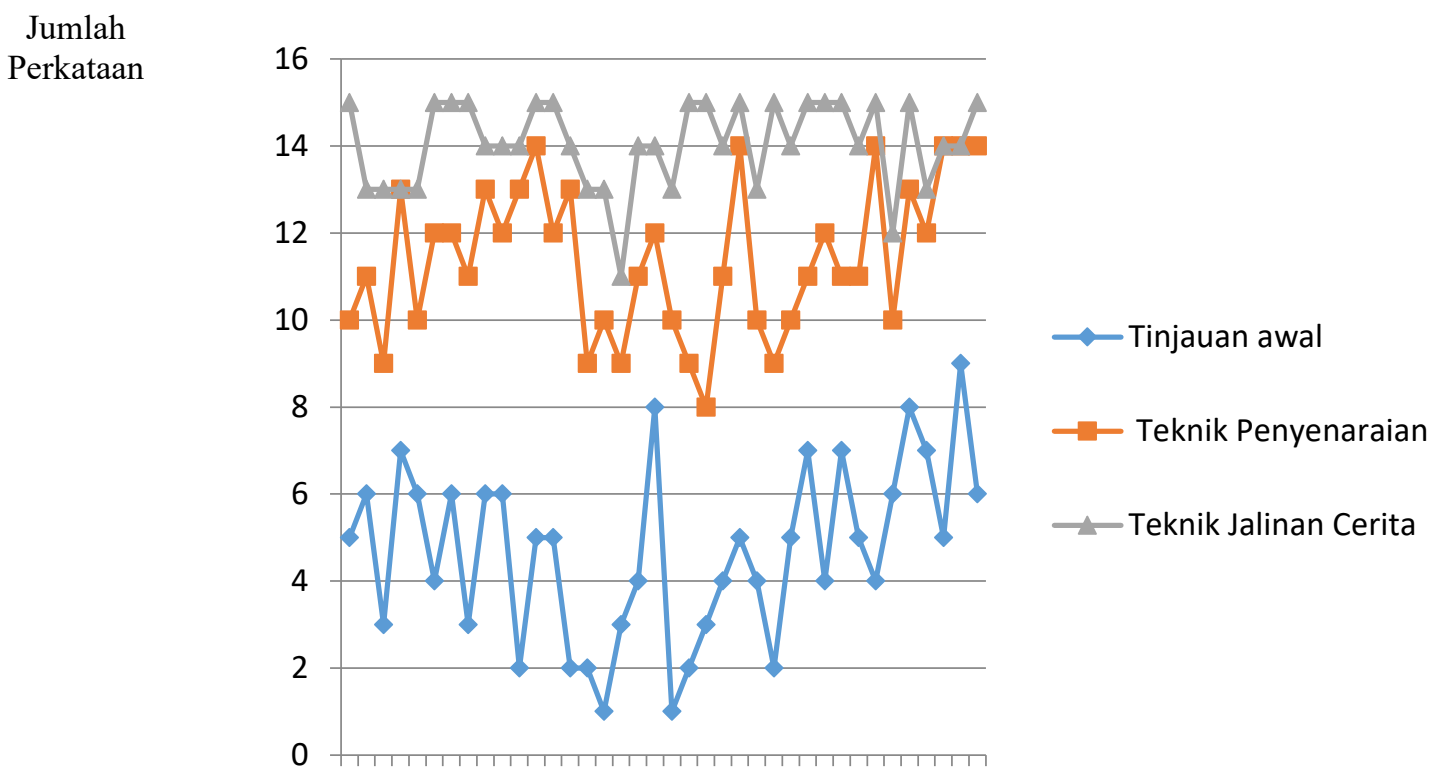

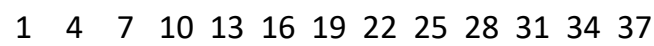

Jumlah Peserta Kajian

RAJAH 9: Perbandingan Pencapaian Tinjauan awal, Penyenaraian dan Teknik Jalinan Cerita.

Berdasarkan Rajah 9 di atas, dapat ditunjukkan bahawa "Teknik Jalinan Cerita" telah dapat membantu kesemua 38 orang peserta kajian menguasai tidak kurang daripada 10 kata majmuk bentuk mantap, malah sebanyak 17 orang telah memberikan kesemua 15 kata majmuk tersebut. Pencapaian ini tidak dapat ditunjukkan oleh mereka sebelum "Teknik Jalinan Cerita" diaplikasikan kerana hasil tinjauan awal menunjukkan bahawa hanya seorang pelajar dapat mencapai sembilan kata majmuk mantap dan yang selebihnya kurang daripada itu. Walaupun teknik penyenaraian yang diaplikasikan sebelum "Teknik Jalinan Cerita" juga meningkatkan pencapaian pelajar tetapi kesannya tidak sebaik dengan kesan daripada "Teknik Jalinan Cerita".

Bagi mengesahkan peserta kajian menggunakan "Teknik Jalinan Cerita" semasa menulis kata majmuk mantap yang dikatakan berjaya ini. Soalan (2) dikemukakan kepada mereka [Sila rujuk Rajah (8), Soalan (2)]. Dapatan daripada Soalan (2) tersebut ditunjukkan dalam Jadual 1 seperti yang berikut:

JADUAL 1: Jawapan Peserta Kajian tentang Soalan (2)

\begin{tabular}{lcc}
\hline \multicolumn{1}{c}{ Soalan (2) } & \multicolumn{2}{c}{ Jawapan Peserta Kajian } \\
\cline { 2 - 3 } & Ya & Tidak \\
\hline Adakah anda membayangkan slaid tersebut (jalinan & 38 orang & - \\
cerita) semasa mencuba menulis 15 kata majmuk & $(100 \%)$ & \\
bentuk mantap? & & \\
\hline
\end{tabular}


Penggunaan "Teknik Jalinan Cerita" untuk meningkatkan penguasaan dan ingatan pelajar terhadap kata majmuk bentuk mantap

Berdasarkan Jadual 1 di atas, ditunjukkan bahawa kesemua (38 orang) peserta kajian menyatakan bahawa mereka membayangkan slaid (Rajah 4: Jalinan Cerita 15 daripada Kata Majmuk Bentuk Mantap) tersebut semasa mencuba menulis 15 kata majmuk bentuk mantap. Tidak ada seorang pun daripada mereka menyatakan diri mereka menggunakan cara lain selain "jalinan cerita" yang telah diperkenalkan.

\section{Kesan “Teknik Jalinan Cerita” untuk Meningkatkan Ingatan Pelajar tentang Kata Majmuk Bentuk Mantap}

Melalui "ujian mengejut" yang dijalankan terhadap kesemua 38 peserta kajian melalui lembaran kerja setelah tiga bulan "Teknik Jalinan Cerita" diperkenalkan, hasil analisis digambarkan melalui Rajah 10 yang berikut:

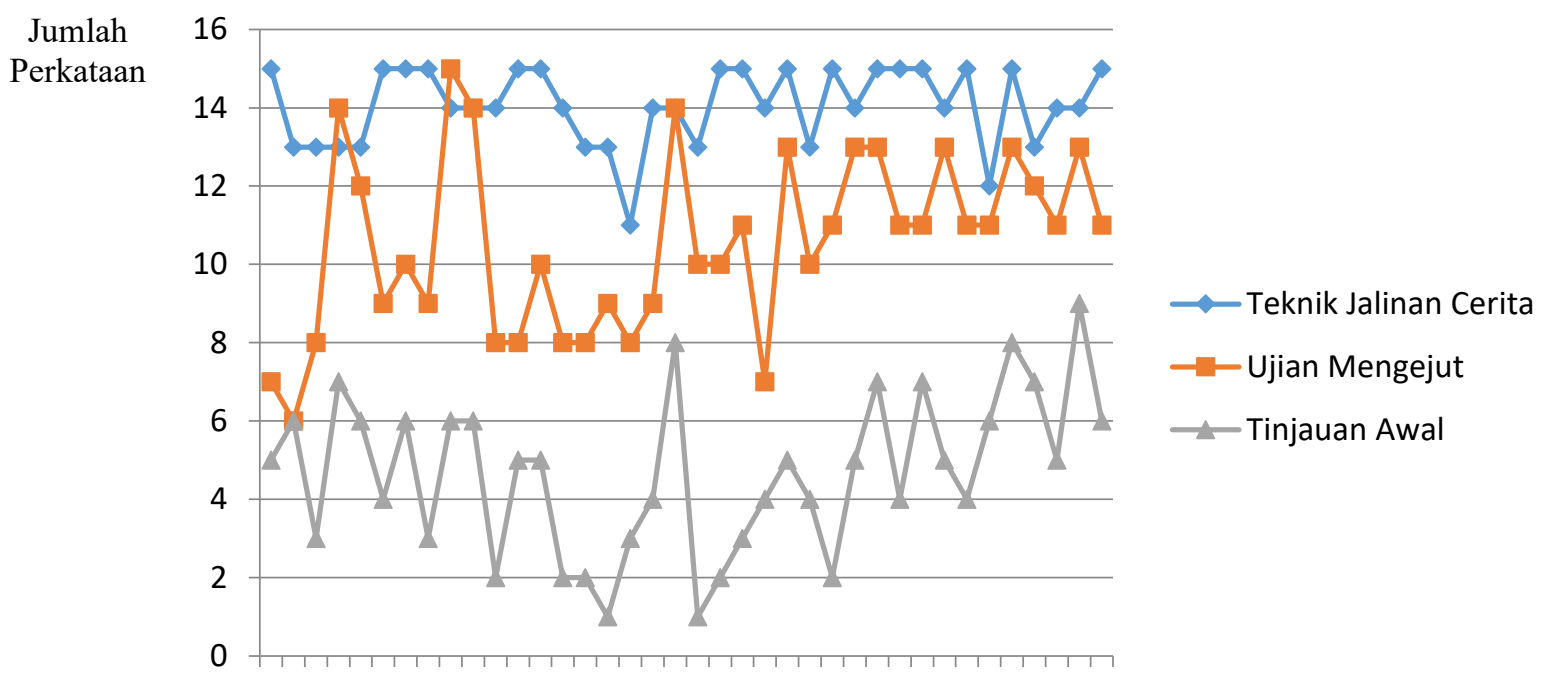

$1 \quad 3 \quad 577921113151719212325272931333537$

Jumlah Peserta Kajian

RAJAH 10: Perbandingan Pencapaian Ujian Mengejut, Teknik Jalinan Cerita dan Tinjauan Awal

Berdasarkan Rajah 10 di atas, dapat ditunjukkan bahawa setelah tiga bulan "Teknik Jalinan Cerita" diaplikasikan, peserta kajian tidak dapat mengekalkan pencapaian terdahulu, iaitu sebaik-baik sahaja teknik tersebut dijalankan. Setelah tiga bulan, mereka telah lupa akan sebahagian kata majmuk bentuk mantap. Walau bagaimanapun, pencapaian mereka jauh lebih baik daripada pencapaian semasa tinjauan awal dijalankan.

Penambahbaikan Amalan Pedagogi Guru dalam Pengajaran Kata Majmuk Bentuk Mantap melalui Penggunaan "Teknik Jalinan Cerita"

Sesungguhnya, penggunaan "Teknik Jalinan Cerita" daripada kata majmuk bentuk mantap yang terancang dan tersusun membawa kelebihan berbanding dengan paparan contoh-contoh kata majmuk bentuk mantap secara penyenaraian yang tidak tersusun. Hal ini dapat ditunjukkan melalui Jadual 2 seperti yang berikut: 
JADUAL 2: Jawapan Peserta Kajian terhadap Soalan (1)

\begin{tabular}{lcccc}
\hline \multicolumn{1}{c}{ Soalan (1) } & \multicolumn{3}{c}{ Jawapan Peserta Kajian } \\
\cline { 2 - 4 } & $\begin{array}{c}\text { Tidak } \\
\text { setuju }\end{array}$ & $\begin{array}{c}\text { Kurang } \\
\text { setuju }\end{array}$ & Setuju & Sangat Setuju \\
\hline Slaid jalinan cerita sangat membantu saya menguasai & & & 12 orang & $(26$ orang) \\
15 kata majmuk bentuk mantap & & $(31.5 \%)$ & $(68.5 \%)$ \\
\hline
\end{tabular}

Berdasarkan Jadual 2 di atas, ditunjukkan bahawa 26 orang atau $68.5 \%$ daripada peserta kajian sangat bersetuju bahawa slaid tersebut sangat membantu mereka menguasai 15 kata majmuk bentuk mantap manakala 12 orang atau (31.5\%) bersetuju mengenainya. Apabila kesemua peserta kajian ditanya tentang "Teknik Jalinan Cerita" yang diperkenalkan kepada mereka [Sila rujuk Soalan (3), Rajah 8], antara pandangan mereka adalah seperti yang berikut:

- Saya lebih mudah ingat memandangkan kata majmuk mantap telah dijadikan satu cerita.

- Memudahkan saya untuk mengingat dengan cara yang lebih teratur.

- Mempunyai jalan cerita yang sangat memudahkan proses mengingat.

- Sangat membantu para pelajar dalam proses mengingat 15 kata majmuk bentuk mantap kerana merupakan satu ayat.

- Kreatif dan mudah untuk diingati.

Walau bagaimanapun, empat daripada 12 orang yang bersetuju tersebut mempunyai pandangan yang sedikit berbeza, iaitu:

- Memudahkan pelajar untuk mengingati cuma saya perlukan masa untuk menghafal.

- Jika ayat tersebut diujarkan denga intonasi dan tidak terlalu mendatar, lebih mudah diingati kerana ini salah satu kaedah baharu untuk mengingat.

- Boleh mengingat dengan cepat tetapi tidak kesemua kata majmuk.

- Agak memerlukan masa dan perlu diulang agar mudah ingat.

Oleh hal demikian, beberapa perkara penting daripada maklum balas peserta kajian perlu saya berikan perhatian dan ditambah baik semasa mengajarkan kata majmuk bentuk mantap melalui "Teknik Jalinan Cerita" ini. Antaranya termasuklah pelajar memerlukan masa untuk menghafalnya bagi membolehkan mereka mencapai skor yang lebih tinggi. Bagi memperkukuh ingatan ini, para peserta harus diberikan peluang untuk melakonkan watak "pesuruhjaya suruhanjaya matahari" ini agar lebih banyak melibatkan pelbagai deria. Hal ini kerana pelajar masih menyatakan mereka perlu mengingati 15 kata tersebut. Melalui jawapan dalam lembaran kerja tersebut, didapati bahawa mereka tidak menyenaraikan kata majmuk secara urutan sebagaimana jalinan cerita yang saya berikan menggambarkan penyusunan yang tidak sistematik dalam minda mereka tentang jalan cerita tersebut walaupun peserta mengakui bahawa mereka membayangkan slaid tersebut semasa menyenaraikan 15 kata majmuk tersebut.

Selain itu, latih tubi juga penting bagi memantapkan latihan semasa "Teknik Jalinan Cerita" dilaksanakan. Penggunaan "Teknik Jalinan Cerita" dapat meningkatkan penguasaan kata majmuk bentuk mantap dalam kalangan pelajar tetapi kurang berjaya mengekalkan daya ingatan terhadap sesuatu yang telah dikuasai. Hal ini dapat dilihat melalui "ujian mengejut" yang telah diberikan. Hal ini ada kaitan dengan pendapat Mohd. Ghani Awang (1996) bahawa ulangan-merupakan suatu proses untuk membiasakan maklumat dengan diri anda. Proses ulangan ini meliputi belajar, belajar semula, ulang kaji, ingatan semula. Kajian ini berpendapat bahawa sepatutnya peserta kajian diberi peluang membaca cerita tersebut berulangulang sehingga mereka dapat menghafalnya sebagai satu cerita yang padu. 
Penggunaan "Teknik Jalinan Cerita" untuk meningkatkan penguasaan dan ingatan pelajar terhadap kata majmuk bentuk mantap

\section{KESIMPULAN}

Pengajaran dan pembelajaran melalui "Teknik Jalinan Cerita" memberikan kesan positif kepada peserta kajian. Teknik ini telah berjaya meningkatkan pencapaian objektif pengajaran saya serta memperkukuh pengetahuan dan minat belajar dan penglibatan pelajar dalam PdP saya. Melalui teknik ini, pelajar bukan sahaja dapat meningkatkan penguasaan diri tentang kata majmuk mantap, malah mereka menyatakan keseronokan melalui pengalaman pembelajaran tersebut. Melalui maklum balas peserta kajian, tidak dapat dinafikan teknik ini masih perlu ditambah baik dengan memasukkan elemen lain seperti latih tubi dalam jangka masa yang lebih panjang.

Melalui kajian tindakan ini, saya dapat menggunakan teknik alternatif lain yang lebih sesuai dengan minat dan kemampuan peserta kajian kerana teknik bercerita sememangnya dapat menarik perhatian dalam PdP. Peserta kajian dapat menunjukkan pencapaian yang memberangsangkan dalam masa yang singkat walaupun bukan semua mampu menyenaraikan kesemua kata majmuk bentuk mantap tersebut. Dengan ini, kajian tindakan ini memberikan dorongan dan keyakinan kepada saya khususnya dalam amalan profesional diri. Setiap kata majmuk bentuk mantap yang asalnya tidak berkaitan antara satu sama lain kemudiannya dijalinkan menjadi satu cerita dalam satu ayat secara padu dapat meningkatkan penguasaan pelajar terhadap sesuatu maklumat penting dalam pelajaran. Pengalaman daripada kajian ini membolehkan saya berkongsi dengan guru praperkhidmatan dan rakan sejawat yang lain.

Pencapaian yang ditunjukkan oleh peserta kajian dalam kajian ini juga telah mendorong saya untuk melakukan kajian lain yang berkaitan dengan teknik pengajaran sebagai kitaran seterusnya. Oleh sebab saya hanya memfokuskan kata majmuk bentuk mantap dalam kajian ini, maka saya belum pasti tentang kesan penggunaan jalinan cerita ini bagi tajuk lain dalam pengajaran bahasa Melayu. Oleh itu, saya akan menambah baik kaedah ini dan mencuba kaedah ini bagi tajuk-tajuk pelajaran lain pada masa akan datang.

\section{RUJUKAN}

Alizah Lambri \& Zamri Mahamod (2015). Pelaksanaan aktiviti pembelajaran berasaskan masalah dalam proses pengajaran dan pembelajaran bahasa Melayu. Pendeta: Jurnal Bahasa, Pendidikan Dan Sastera Melayu, 6, 98 - 117. Retrieved from http://ejournal.upsi.edu.my/index.php/PENDETA/article/view/1160 [ 10 DISEMBER 2019]

Bailey, K.D. (1984). Kaedah penyelidikan sosial. Terj. Hashim Awang. Kuala Lumpur: Dewan Bahasa dan Pustaka.

DeNeen, J. (2012). 30 storytelling tips for educators: How to capture your student's attention. Diakses daripada https://www.opencolleges.edu.au/informed/features/30-storytelling-tips-for-educators/ $\quad[5$ DISEMBER 2019]

González, N. I. P. (2010). Teaching english through stories: A meaningful and fun way for children to learn the language. PROFILE Issues in Teachers' Professional Development. Vol. 12 (1). $2010 \mathrm{http}: / / \mathrm{dx}$.doi.org/10.15446/profile

Liu, S. (2016). The power of storytelling in the classroom: 5 ways it can be a great help. Diakses daripada https://teach.com/great-educational-resources-the-power-of-storytelling/_ [ 5 DISEMBER 2019]

Loi, K. S (2012). Kesan penggunaan kaedah bercerita dalam proses pengajaran dan pembelajaran sains tahun lima. Koleksi Artikel Penyelidikan Tindakan PISMP SN Amb. Januari 2009, Seminar Penyelidikan Tindakan IPGKBL Tahun 2012, ms.102-115

Maizan Mat@Muhammad (2017). Teknik mnemonik sebagai strategi kognitif dalam meningkatkan keupayaan ingatan pelajar peringkat pengajian Pra-U: Sorotan kajian lepas. Proceeding National Pre University Seminar 2017 (NpreUS2017) RHR Hotel, 23 Ogos 2017. Dimuat turun daripada http://conference.kuis.edu.my/npreus/2017/document/35Maizan\%20binti\%20Mat@Muhammad.pdf (16 OGOS 2018)

Merriam, S. B. (1998). Qualitative research and case study applications in education (2nd ed.). San Francisco: JosseyBass.

Mohd. Ghani Awang (1996). Kemahiran belajar di Institut Pengajian Tinggi. Kuala Lumpur: Dewan Bahasa dan Pustaka. 
Nik Safiah Karim, Farid M. Onn, Hashim Musa \& Abdul Hamid Mahmood (2014). Tatabahasa dewan edisi ketiga. Kuala Lumpur: Dewan Bahasa dan Pustaka.

Nguyen, K., Stanley, N., Stanley, L. (2014). Storytelling in teaching Chinese as a second/foreign language. Linguistics and Literature Studies 2(1): 29-38, 2014. DOI: 10.13189/1ls.2014.020104

Othman Mohamed (2001). Penulisan tesis dalam bidang sains sosial terapan. Serdang: Universiti Putra Malaysia.

Powell, R. M. \& Murray, O. (2012). Using storytelling strategies to improve student comprehension in online classes. The Journal of Effective Teaching, Vol. 12, No. 1, 2012, 46-52. Dimuat turun daripada https://files.eric.ed.gov/fulltext/EJ1092135.pdf [ 5 DISEMBER 2019]

Ramlan Hamzah \& Lily Mastura Harun (2005). Kemahiran belajar untuk Kursus Persediaan Ijazah Sarjana Pendidikan. Kuala Lumpur: Kumpulan Budiman Sdn. Bhd.

Shahabuddin Hashim, Rohizani Yaakub \& Mohd Zohir Ahmad (2007). Pedagogi: strategi dan teknik mengajar dengan berkesan. Kuala Lumpur: PTS Professional.

Siti Zuhaida Zakeria \& Nik Rafidah Nik Muhamad Affendi (2014). Konflik dalam cerita rakyat dan kesannya kepada kanak-kanak. Pendeta: Jurnal Bahasa, Pendidikan Dan Sastera Melayu, 5, 185 - 206. Diakses daripada http://ejournal.upsi.edu.my/index.php/PENDETA/article/view/1201 [ 10 DISEMBER 2019]

Tay, M.G. \& Wong, S. H. (2016). Minat pelajar bukan penutur natif terhadap pembelajaran bahasa Melayu: Satu Kajian Kes. Jurnal Penyelidikan IPGKBL. 13, 53-63.

Zulkifli Osman, Anida Sarudin, Dahlia Janan dan Ani Omar (2016). Keberkesanan pendekatan autentik dalam meningkatkan tahap penulisan karangan pelajar. Pendeta: Jurnal Bahasa, Pendidikan Dan Sastera Melayu, 7, 142 - 155. Retrieved from http://ejournal.upsi.edu.my/index.php/PENDETA/article/view/1210 [10 DISEMBER 2019].

Zuraini Jusoh \& Abdul Rashid Jamian (2014). Kesan bercerita terhadap pencapaian penulisan karangan naratif bahasa Melayu. Jurnal Pendidikan Bahasa Melayu - JPBM. Vol. 4, Bil. 1 (Mei 2014): 11-18. Diakses daripada http://journalarticle.ukm.my/7109/1/11-18_Zuriani_et_al.UPM.pdf ( 5 APRIL 2018) 